\title{
Unacknowledged Caregivers: A Scoping Review of Research on Caregiving Youth in the United States
}

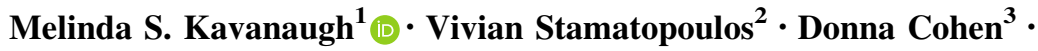 \\ Lixia Zhang ${ }^{4}$
}

Received: 26 August 2015/Accepted: 31 August 2015/Published online: 14 September 2015

(C) Springer International Publishing 2015

\begin{abstract}
With over 43 million family caregivers living in the United States, families are the largest providers of informal care in this country. Despite the extensive caregiving literature about prevalence, characteristics of care providers and care recipients, risks to caregivers' health and well-being, economic costs, impact on personal and family well-being, evidence-based interventions, and model community-based programs and supports for adult caregivers, gaps exist, specifically relating to caregiving youth, i.e., children under the age of 18 years. With no previous comprehensive review to assess what is known about US youth caregivers, a scoping review, focusing on mapping the key concepts, including the main sources and types of evidence available, was undertaken. By drawing conclusions about the overall state of research activity and identifying research gaps and priorities in the existing literature, this study provides a baseline assessment of youth caregiver research published in peer-reviewed journals from 1996 to 2015. A total of 22 articles were included in the analysis. Beyond inconsistencies with naming and defining young/youth caregivers, the review found
\end{abstract}

Melinda S. Kavanaugh

kavanaug@uwm.edu

1 Helen Bader School of Social Welfare, University of Wisconsin - Milwaukee, PO Box 786, Enderis Hall, Rm 1045, Milwaukee, WI 53201, USA

2 Department of Sociology, York University, Toronto, ON, Canada

3 Violence and Injury Prevention Program, Department of Child and Family Studies, College of Behavioral and Community Sciences, University of South Florida, Tampa, FL, USA

4 Helen Bader School of Social Welfare, University of Wisconsin - Milwaukee, Milwaukee, WI 53201, USA significant knowledge gaps in crucial areas including SES status of families who rely on caregiving youth, the role of race, ethnicity and culture, support across schools, communities and medical professions, and the lack of caregiving programs and polices inclusive of youth under 18 . The results underscore the need for further inquiry, including longitudinal study, into the lives and experiences of caregiving youth, informing the development of youth caregiver focused supports and polices across the US.

Keywords Young carer - Young caregiver - Caregiving youth $\cdot$ Scoping review

\section{Introduction}

Over the past decade, several national surveys have reported between 36 and 65 million family caregivers in the United States (US), but the latest survey indicated an estimated 44 million family caregivers [National Alliance for Caregiving (NAC)/AARP 2015], making families the largest providers of informal care in the US. Well over 2000 published studies have provided an extensive base for understanding the family caregiving context (see reviews Schulz and Martire 2004; Feinberg 2006), and they are primarily focused on spouses and adult children caring for older relatives (Schulz et al. 1995; Given et al. 2004) as well as parents caring for ill and disabled children (Klassen et al. 2007; Sulkers et al. 2015). Results of these studies describe strains, burdens and negative emotional and physical outcomes of caregiving (Haley 1997; Stetz and Brown 2004; Schulz and Martire 2004; Heru and Ryan 2006), as well as the potential for positive impacts of caregiving (Kramer 1997; Cohen et al. 2002). This large body of research has informed numerous state and national 
interventions for family members caring for elders and young children, providing a pathway for policies and largescale services targeted at improving the lives of elder and young parent family caregivers (Feinberg and Newman 2006).

Largely excluded from the years of caregiving research, policy, and program development are caregivers under the age of 18 years. This age group, referred to as "caregiving youth" in US studies and "young carers" in the global literature, are providing substantial care, usually on a longterm basis, to dependent family members of all ages who have physical and mental health conditions, disabilities, frailty, and other problems. Yet, despite the intense care provided, and potential long term complicated impacts of caregiving, they remain an isolated and understudied adolescent population.

\section{Caregiving Youth}

Involvement of children/youth in household activities is integral to normative interactions and expected family contributions to family life (Friedman et al. 2003). Moreover, helping with household duties provides a healthy way for children to learn responsibility and modeling of adult roles (Boszormenyi-Nagy and Sparks 1973). However, household activities can go beyond household chores, transitioning to caregiving tasks including personal, emotional, and physical caregiving, shifting children from helping in the home to managing households and providing care usually performed by adults. These children and adolescents have largely been overlooked as potential providers of care.

\section{International Young Carer Research}

Young carers have been identified and studied in the United Kingdom (UK), Australia, Africa, several European and Asian countries, as well as Canada, and the prevalence, characteristics, contributions, and support needs for this population are beginning to be acknowledged in both policy and programming. In order to understand the current state of caregiving youth affairs in the US however, we must first situate what is known within the context of the larger global body of research and awareness. Becker's (2007) global analysis of young carer movements provides a jumping off framework to achieve this aim.

Becker (2007) examined four countries using a typology characterizing national levels of young carer awareness and policy response on a scale ranging from advanced to preliminary. The UK was the most advanced country in addition to being the founding nation of the young carer movement. Not only have young carers been "well and truly placed on the map of child welfare services"
(Newman 2002, p. 614) since the mid-1990s, but there are also over 350 dedicated young carer projects servicing more than 25,000 young carers while employing hundreds of workers and volunteers (Becker 2007). Young carers also have legal rights to an assessment of their personal needs and their ability to provide and continue to provide care, having the option of direct cash payments in lieu of services should they choose to coordinate their own care plans. Australia held an "intermediate" designation because of a track record of heightened national awareness and recognition of young carers since 2000, among policy makers, professionals, and the general public. Coordinated policy actions have also led to the creation of partial legal rights and increasing young carer-specific interventions (Becker 2007). The US was ranked as "preliminary" because of its limited recognition of the existence of caregiving youth and minimal research coinciding with only a handful of dedicated local services. Helping to edge the US past an emerging position, however, was the development of the American Association of Caregiving Youth (AACY) in 1998, and the national prevalence study estimating the presence of 1.3-1.4 million child caregivers between ages 8 and 18 years in the US [National Alliance for Caregiving/United Hospital Fund (NAC/UHF) National Alliance for Caregiving/United Hospital Fund 2005]. This is contrasted with Sub-Saharan Africa whose "emerging" position was characterised by an embryonic awareness of young carers as a distinct social group within the "vulnerable children" population, relating to the effects of HIV/ AIDS on young carers (Becker 2007).

As a result of the awareness raising and research results borne out of the contributions of these four countries, additional nations have begun acknowledging youth as both potential providers and receivers of care. The most advanced of the new countries is Canada, which can be seen holding a "preliminary" designation because of the operation of a handful of dedicated young carer programs that have assisted an estimated 1250 young carers since their inception in 2005 (Stamatopoulos 2015b). Germany holds a place somewhere between "emerging" and "preliminary" because of a small but developing research base and the existence of one official young carer project funded by the German Federal Ministry of Education and Research (Schlarmann et al. 2011). A growing number of European countries may soon be added to the typology, because a small group of researchers and social service providers from Iceland, Italy, the Netherlands, Norway, and Sweden are developing an interest in caregiving youth, although no known dedicated programs exist to support their specific caregiving roles.

While international research may provide valuable insights into the lives of young carers, differences in government legislation and programs as well as sociocultural 
differences between countries do not allow for parallels and assumptions about impacts of caregiving to be made between young carers in each country. Moreover, apart from the UK and Australia, whose registered young carer projects are housed on the UK's National Health Service (NHS) website and the Carers Australia website, it is difficult to locate all the additional programs and dedicated young carer services to inform directions for support. Reliance on international young carer best practices is important but not necessarily entirely appropriate or available for informing policy and programs in the US. Consequently, an understanding and review of the literature about caregiving youth in the US and the policies affecting caregiving youth is vital.

\section{Youth Caregivers in the US}

The results of the NAC/UHF prevalence study of caregiving youth in the US reported a significant proportion of caregiving youth had an increased likelihood of experiencing school problems and depression compared to their noncaregiving counterparts (NAC/UHF 2005). Unfortunately, 10 years after the release of this report and Beckers' report (2007), the US still maintains a "preliminary" assignment. Caregiving youth are completely hidden from public agendas, as seen in a recent White House program on caregiving (www.whitehouseconferenceonaging.gov), which had no focus on youth. Furthermore, the latest National Caregiving Alliance/AARP caregiver survey did not include caregivers under the age of 18 years (NAC/AARP 2015), while caregiving youth are excluded from federal and state-funded caregiving programs, all of which target adult caregivers exclusively. Historically informing the development of local, state and national programs, the vast adult caregiver research base details the lived experience, support needs, and impacts of caregiving (see Skaff et al. 1996; Schulz and Martire 2004; Savage and Bailey 2004). Caregiving programs and policies are driven by research, including literature reviews, which provide a clear roadmap for future work by detailing the breadth of an issue or population from which polices and programs can be designed.

\section{Current Study}

The body of research on US youth caregivers has yet to be coalesced into a review, leaving a gap in the ability to inform and guide policies and caregiving programs as has been conducted in adult caregiving policies, but targeting caregiving youth. Thus, there exists a need to create a road map and framework for future US youth caregiving research from which to move the caregiving youth research field forward. Offering an "opportunity to identify key concepts, gaps in the research, and types and sources of evidence to inform practice, policymaking, and research" (Daudt et al. 2013, p. 8), a scoping review was conducted to inform that roadmap. With a focus on the breadth of the literature as opposed to a systematic review of detailed interventions and programs, non-existent in US caregiving youth, the scoping review addressed four main research questions: (1) Who is a caregiving youth?; (2) What is the caregiving experience?; (3) How are caregiving and well-being measured?; and (4) What knowledge gaps exist to guide priorities for future research and programming directions?

\section{Methods}

\section{Conceptual Framework}

Following the framework established by Arksey and O'Malley (2005), the goal of this scoping review was to summarize available caregiving youth peer reviewed primary research findings, with the intent to draw conclusions about the state of research activity and identify research gaps in the existing literature without a detailed review of findings or a quality assessment of the studies involved. The scoping review entailed six steps: (1) defining a broad research question or set of questions; (2) identifying the relevant literature about caregiving youth in the US that meet search parameters; (3) selecting the studies meeting the selection criteria; (4) charting the results from accepted articles; (5) summarizing the results and identifying gaps; and (6) a consultation exercise to inform and validate findings from the main scoping review (Oliver 2001). The final step entailed engaging with a known young/youth caregiver expert and professional, gathering feedback about identifying gaps and priorities to validate the overall review (Anderson et al. 2008).

In order to identify the literature, a series of search terms as well as parameters for including articles were developed to review the literature using PubMed, CINHAL, Google Scholar, JSTOR, SocIndex, PsychInfo, academic search, and Web of Science online search engines as well as paper journals when online versions were not available. The consensus from discussions and meetings with research and practice experts in this area was that there was no consistent nomenclature for child and adolescent caregivers. Thus, the following key words were used: "young carer," "young caregivers," "child carers," "children caregivers," "youth caregivers," "caregiving youth," and "adolescent caregivers."

Criteria for accepting articles included the following: Given the focus on primary youth caregiver research, articles had to have been published in a peer-reviewed journal from January 1996 to May 2015; the research had to be conducted at least partially in the US, using US 
samples; in order to separate caregiving from general care of other children in the home or babysitting, research studies must address caregiving for a family member with a physical or mental impairment; data could be collected from parents or care recipients and/or youth caregivers; and qualitative or quantitative methods were both acceptable. Of 25 articles initially retrieved, the review of abstracts revealed 22 publications that included one or more of the search terms and met review criteria. If an abstract was unclear, the full paper was obtained and reviewed to assess whether it would be included in the review.

\section{US Scoping Review Results}

\section{Sources and Types of Evidence}

As shown in Table 1, caregiving youth research is largely descriptive, providing an initial picture of who caregiving youth are, their caregiving experiences, and what measures are used to assess their well-being and relationship with their medically dependent parent or other family member. Sample sizes ranged from seven mothers (Keigher et al. 2005) to over 6000 youth (Siskowski 2006), but the majority contained samples of less than 40 young caregivers.

Much of the data was qualitative, or utilized semi-structured interviews and focus groups designed for the research project (Beach 1997; Gates and Lackey 1998; Jacobson and Wood 2004; Keigher et al. 2005; Williams et al. 2009; Nichols et al. 2013; Kavanaugh 2014; Kavanaugh et al. 2015). Three studies used a secondary dataset, collected as part of the "What Works" survey of 6-12th grade students in Palm Beach County, Florida (Siskowski 2006; Diaz et al. 2007; Cohen et al. 2012). Almost all of the studies were conducted with the caregiving youth themselves, with three studies using the family care-recipient as the interviewee (Jacobson and Wood 2004; Keigher et al. 2005; Bauman et al. 2006). One study used US population and economic data to estimate the economic contributions of youth caregivers (Viola et al. 2012), yet no studies collected data from health care professionals, school personnel, or peers.

\section{Key Concepts}

\section{Defining Caregiving Youth}

Variations in nomenclature were evident across studies. The term "young carer," was used, consistent with the British and Australian research, (Nichols et al. 2013; Kavanaugh 2014; Kavanaugh et al. 2015), while the majority used "young caregivers" (Shifren 2001; Shifren and Kachorek 2003; Keigher et al. 2005; NAC/UHF 2005; Siskowski 2006; Shifren and Chong 2012; Nichols et al.
2013), with "caregiving youth" also embraced by several researchers (Siskowski et al. 2007; Cohen et al. 2012). Shifren and Chong (2012) addressed the lack of consistency in defining child caregivers across studies: "Currently, no general consensus exists for the operational definition of young caregivers... (p. 113)." The existing literature reflects this debate about what it means to be young, including demographic data about these caregivers, relationships with care recipients, the caregiving experience, and the level of care responsibility required to establish caregiver status.

Age

Several studies, including the national prevalence study, used a minimum and maximum age. The national prevalence study (NAC/UHF 2005) and two other studies (Bauman et al. 2006; Nichols et al. 2013) set the minimum age at 8 years, whereas the three studies using data from the Palm Beach Florida "What works" survey (Siskowski 2006; Diaz et al. 2007; Cohen et al. 2012) ranged from 6 to 12th grade (approximately 10-18 years of age). Finally, others, (Gates and Lackey 1998; Lackey and Gates 2001; Nichols et al. 2013) defined the range as 10-19. In the US children are regarded as under age 18 years, but it is clear the maximum age in these studies was not consistent with the national limit, despite their focus on youth and children. Williams et al. (2009) simply said that young caregivers are children who are the ages of minors, while Kavanaugh (2014) referred to young carers as under 19. Shifren and colleagues (Shifren 2001, 2008; Shifren and Kachorek 2003; Shifren and Chong 2012) used individuals who were caregivers aged 21 years and younger.

Even when authors explicitly stated an age range for caregiving youth, their samples sometimes included children with a longer history of caregiving. For example, Lackey and Gates (2001) set initial eligibility for their adult retrospective study at age 10-18 years, yet found that many had been caregivers from ages 3 to 19 years. Diaz et al. (2007) described young caregivers as those who are ages 18 years or younger but were limited by the dataset to children in grades six through twelve. Furthermore, because some studies (Beach 1997; Keigher et al. 2005) did not explicitly define caregiving youth it might be assumed that their sample was simply an embodiment of their definition.

\section{Race/Ethnicity}

Racial and ethnic diversity were represented in the literature, although White Caucasian Americans were the most common constituent (Lackey and Gates 2001; Shifren and Kachorek 2003; NAC/UHF 2005; Shifren 2008; Kavanaugh 2014; Kavanaugh et al. 2015). In a comparison study 


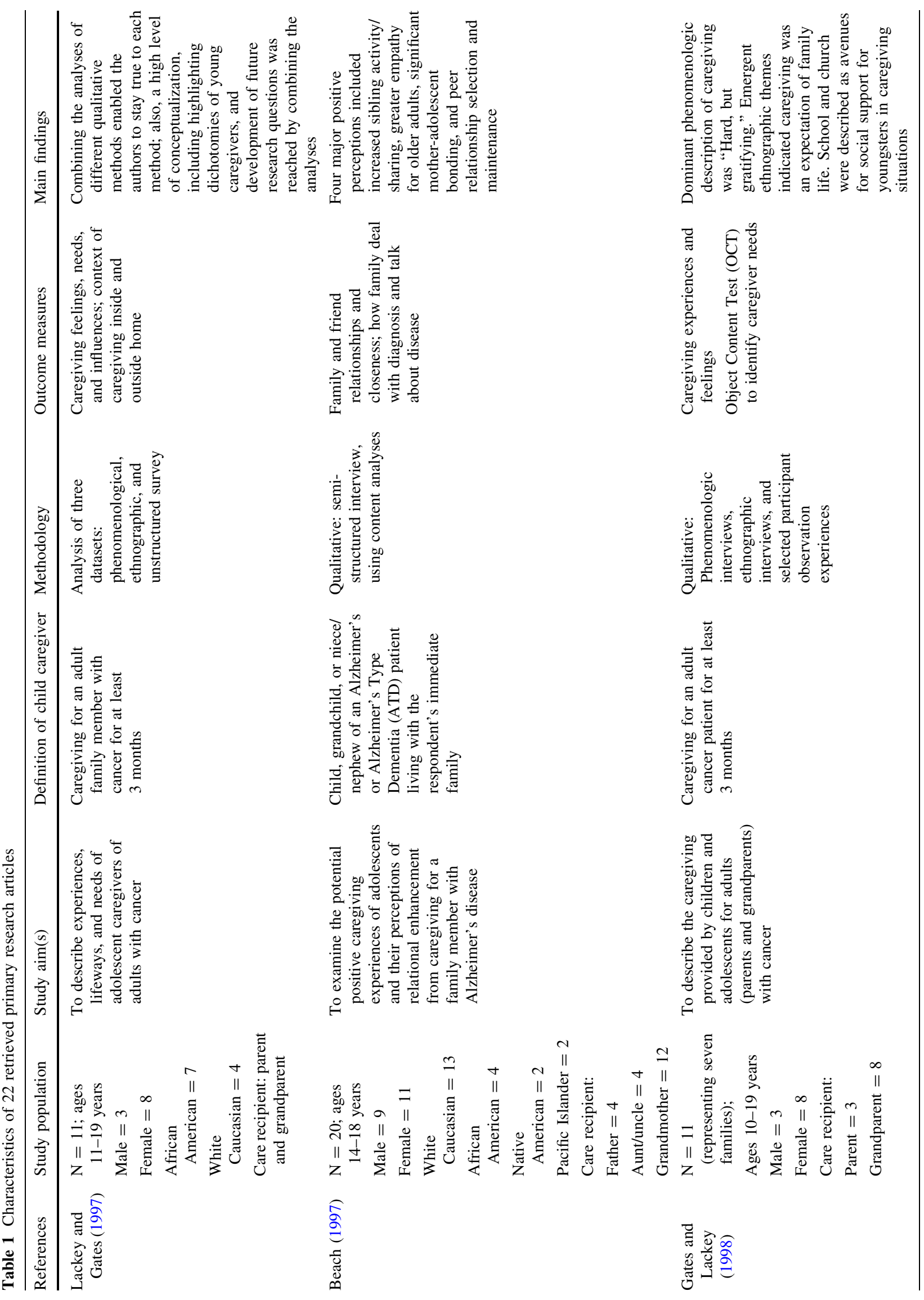




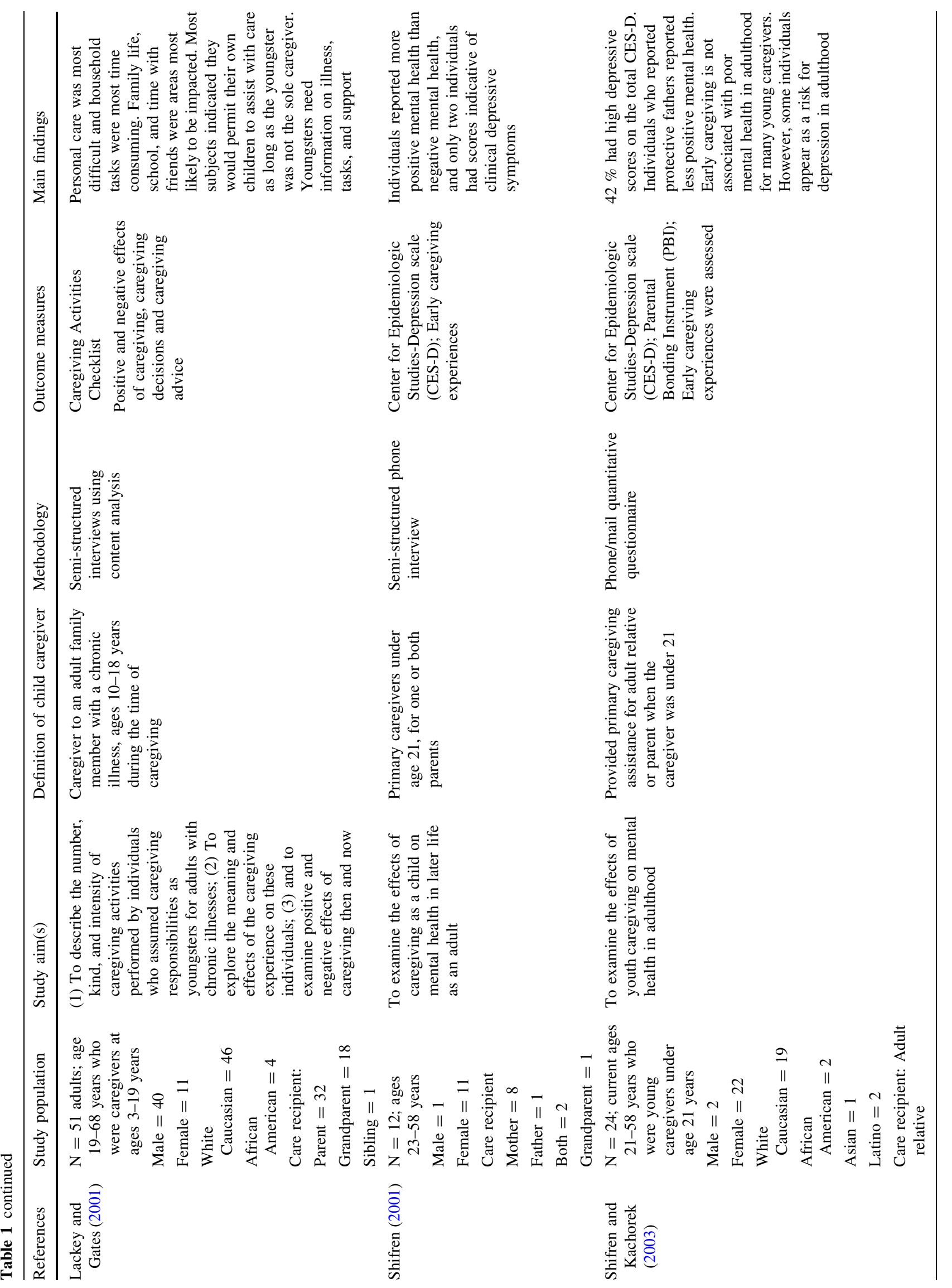




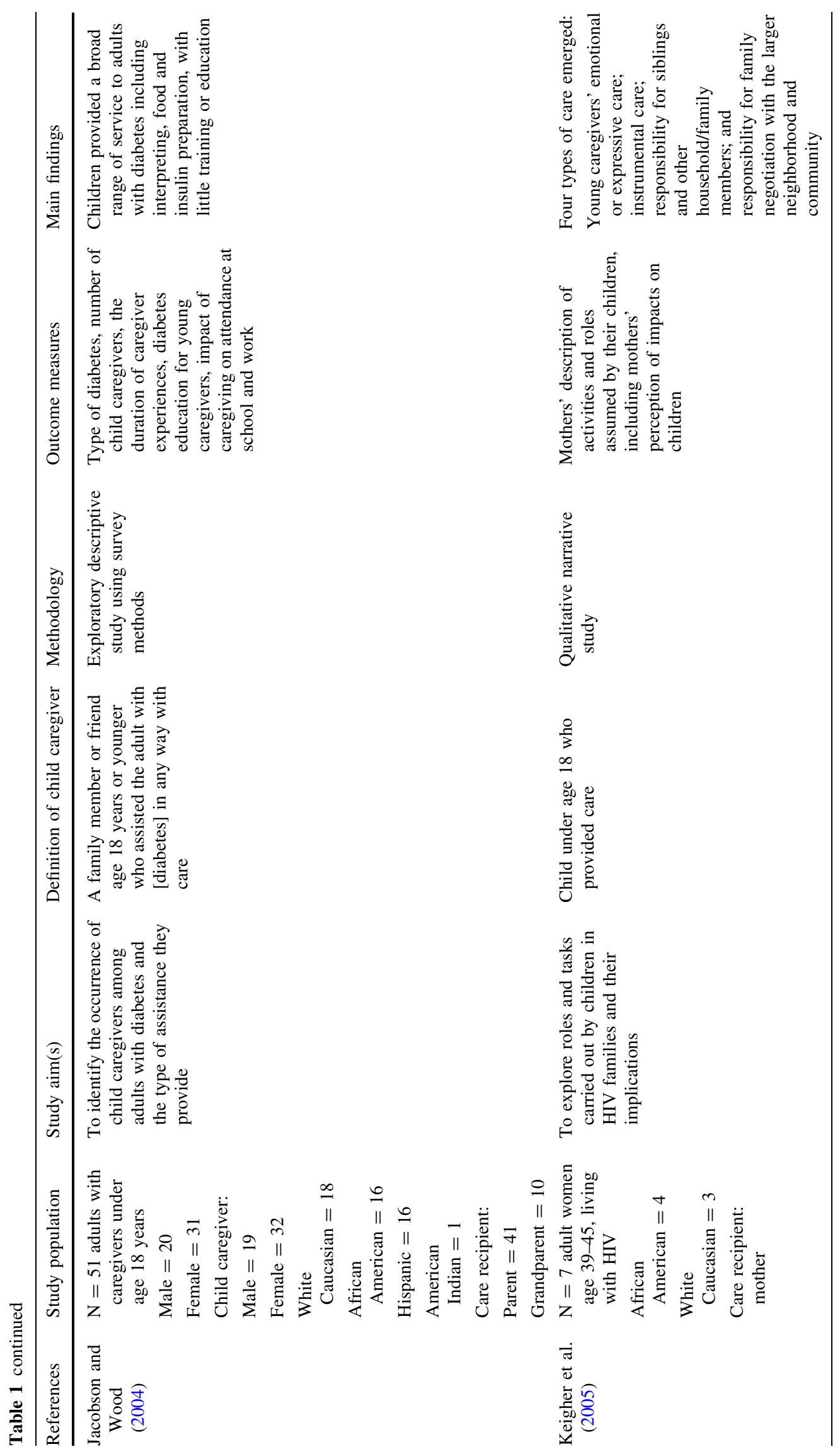




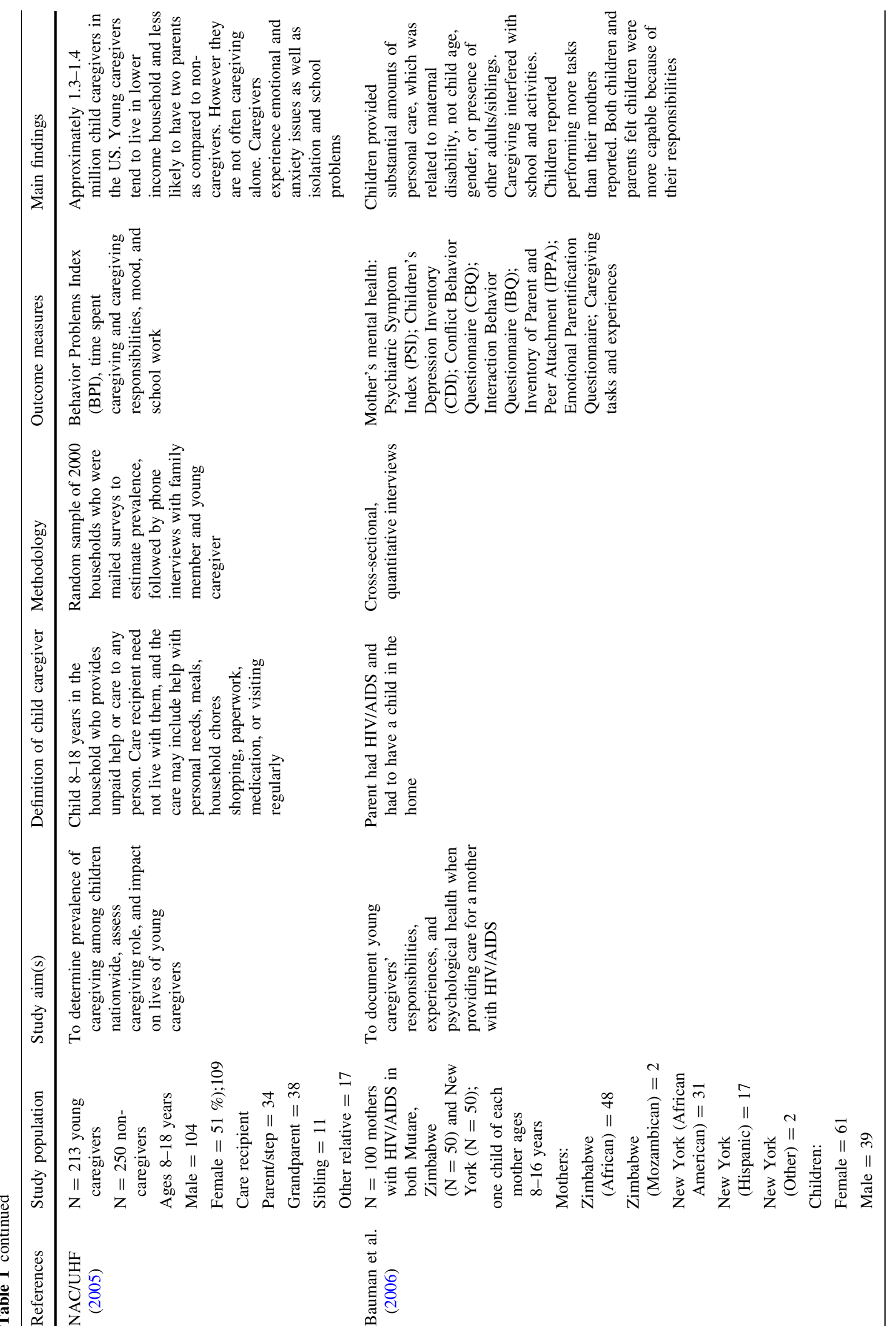




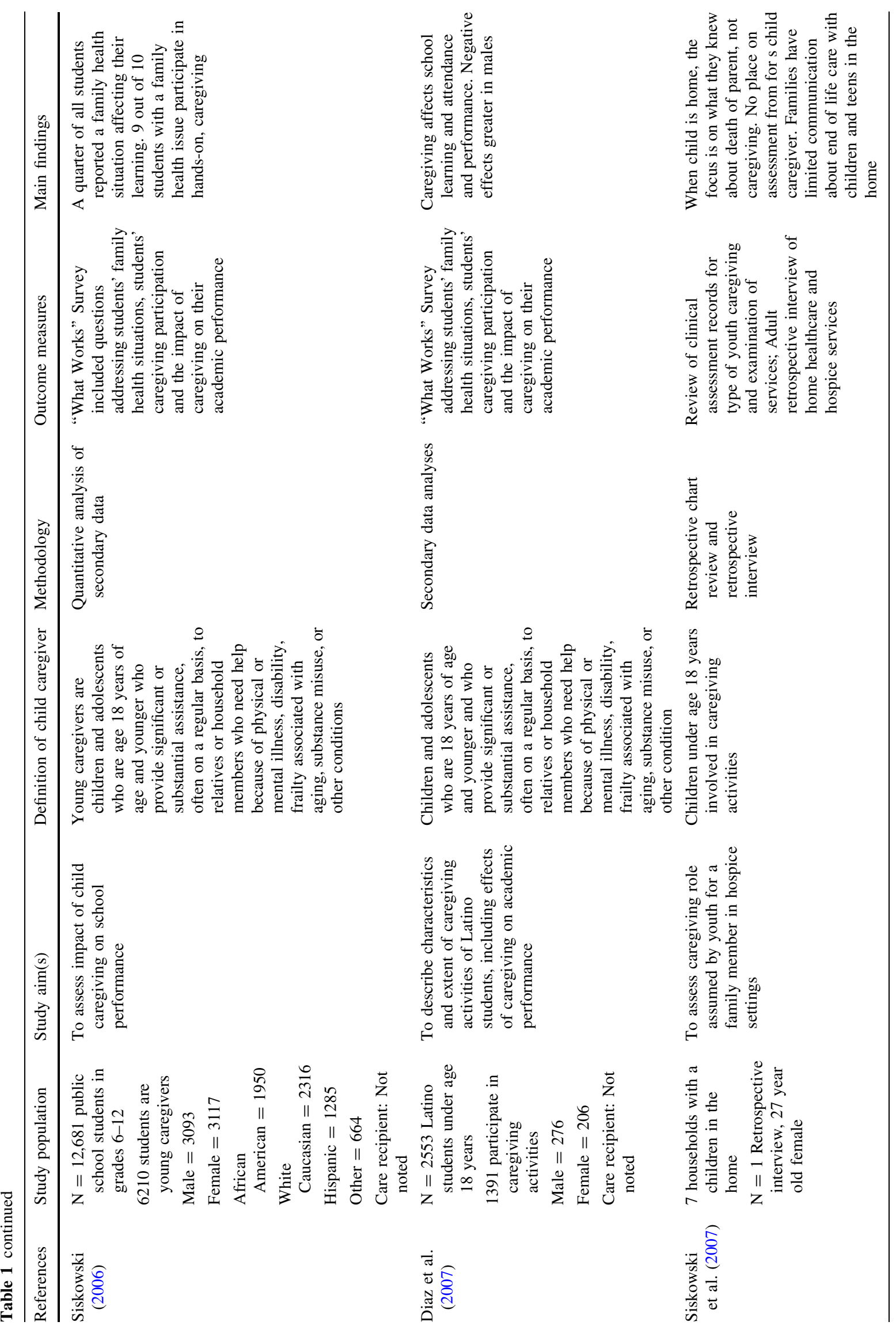




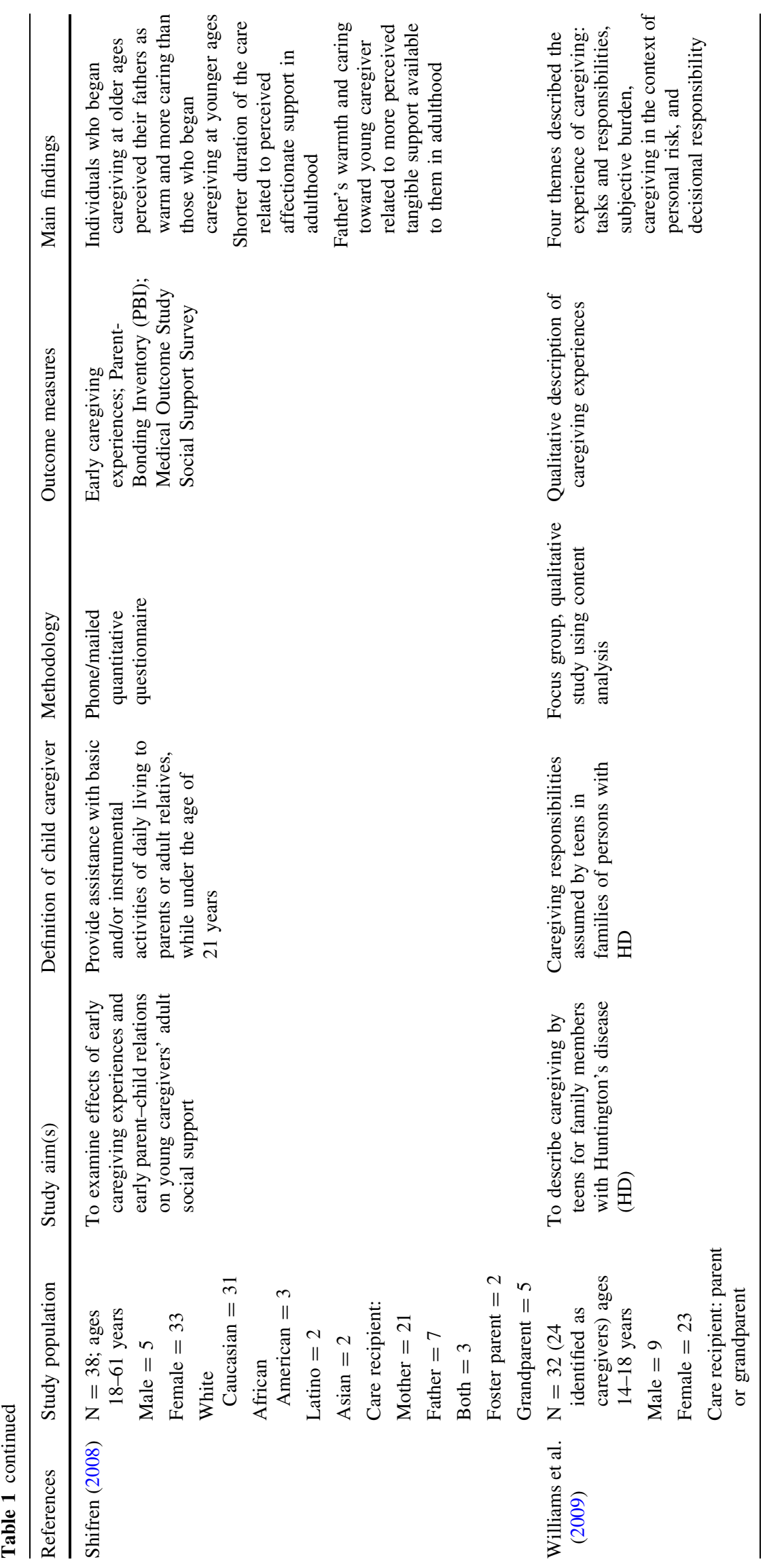




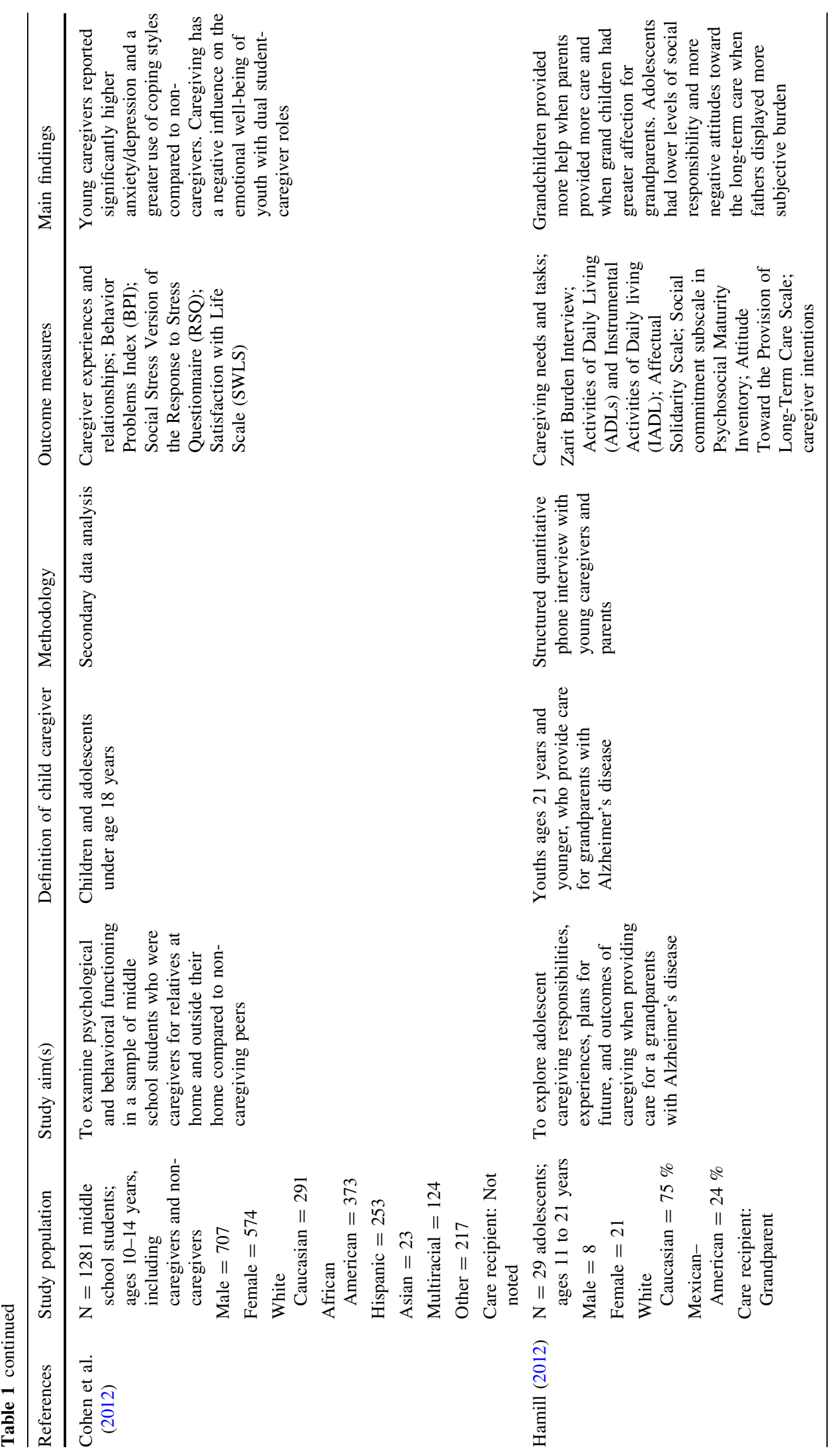




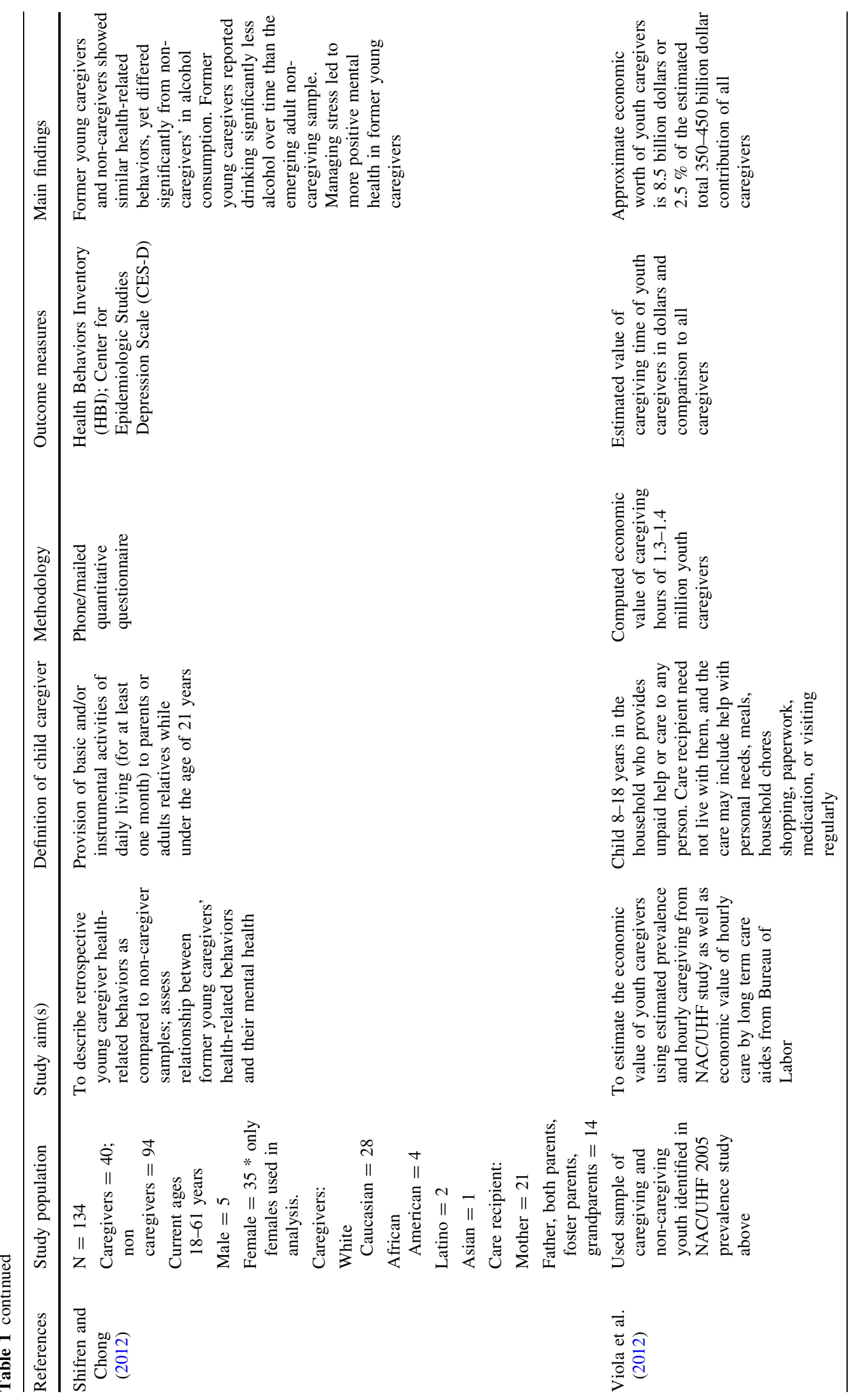




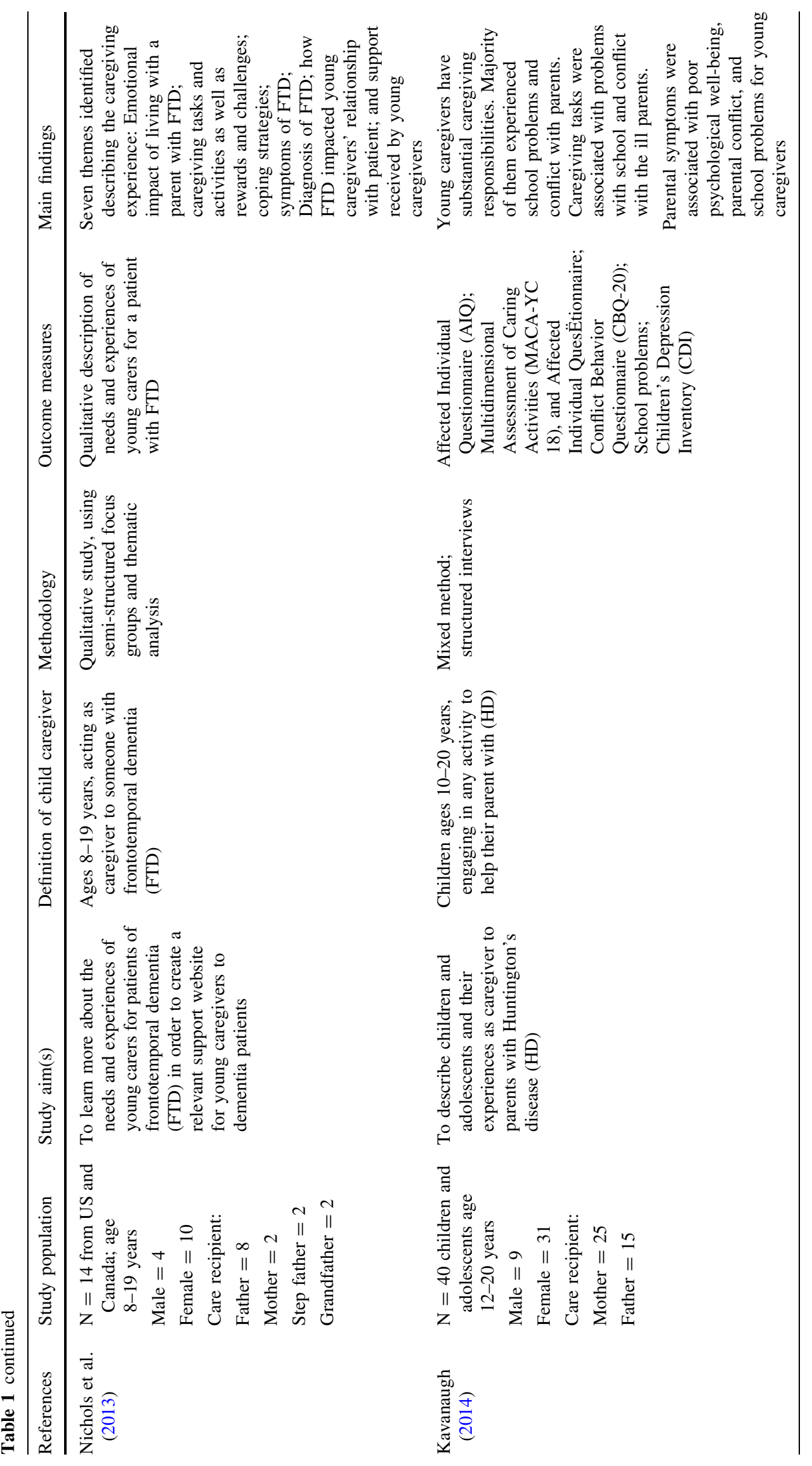




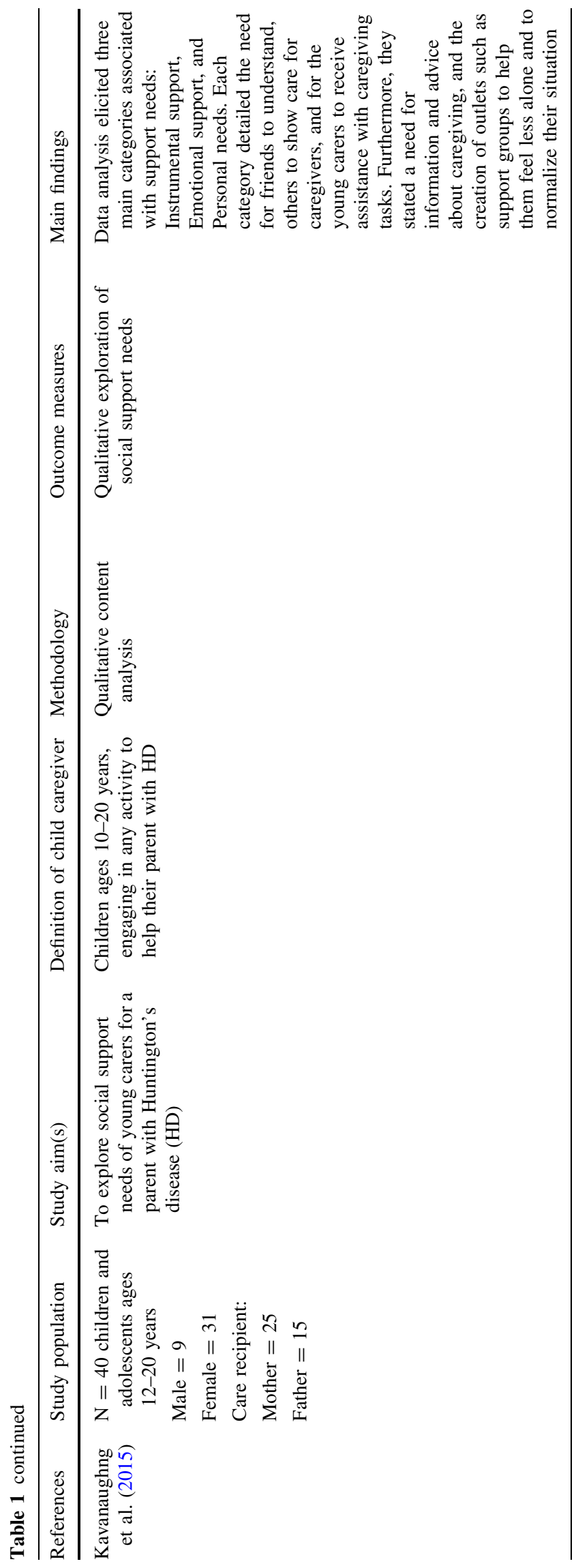

of 50 New York and 50 Zimbabwe young caregivers, $63 \%$ of the New York caregiving population were African American and $33 \%$ were Hispanic, with only $8 \%$ White Caucasian (Bauman et al. 2006). In her analysis of 6210 Palm Beach middle school students who were caregivers, Siskowski (2006) found $31 \%$ of caregivers were African American and Hispanic compared to $37 \%$ who were White Caucasian. Using the same database, Diaz et al. (2007) reported on a sample of 2553 Latino young caregivers, while, Jacobson and Wood (2004), reported $63 \%$ African American and Hispanic, and $35 \%$ White Caucasian.

\section{Relationship and Geographic Proximity to Care Recipient}

Child caregivers were also defined by their relationship to the care recipient - often their parent (Keigher et al. 2005; Bauman et al. 2006; Nichols et al. 2013; Kavanaugh 2014). Grandparents (Beach 1997; Lackey and Gates 2001; NAC/UHF 2005; Shifren 2008; Hamill 2012) adult relatives (Diaz et al. 2007; Shifren and Kachorek 2003; Shifren and Chong 2012), and siblings (NAC/UHF 2005) were also listed as care recipients. Jacobson and Wood (2004) broadly referred to care recipients as family members or friends, although their sample included a large majority $(80 \%)$ of children caring for their parents. Two studies (Beach 1997; Diaz et al. 2007) indicated that caregivers live with their care recipients who may be any family member. While Kavanaugh et al. $(2014,2015)$ and the national prevalence study (NAC/UHF 2005) included caregivers who lived in the same household as the care-receiver in addition to those living in separate residences.

\section{Caregiving Experience}

\section{Care Recipient Illness}

Caregiving youth were confronted with a broad range of illnesses and disabilities that may require a wide variety of care tasks depending on the severity of conditions, comorbidities, length of caregiving, and the presence of more than one care recipient. Some studies focused on children caring for family members with specific medical conditions: HIV/AIDS (Keigher et al. 2005; Bauman et al. 2006), diabetes (Jacobson and Wood 2004), cancer, (Gates and Lackey 1998), Alzheimer's disease (Beach 1997), frontotemporal dementia (Nichols et al. 2013), and Huntington's disease (Williams et al. 2009; Kavanaugh 2014; Kavanaugh et al. 2015). The NAC/UHF (2005) national prevalence study included care recipients with many medical conditions, the most common being Alzheimer's, heart 
disease, arthritis, diabetes and cancers. The remaining studies, including those using the "What Works" dataset in Florida, (Siskowski 2006; Diaz et al. 2007; Cohen et al. 2012), addressed diverse illnesses and disabilities (Lackey and Gates 2001; Shifren and Kachorek 2003; Shifren 2008; Shifren and Chong 2012) and different settings, including hospice (Siskowski et al. 2007) and nursing homes (Kavanaugh 2014).

\section{Caregiving Tasks}

Many of the studies delineated a range of activities of daily living (ADLs) and instrumental activities of daily living (IADLs) (Lackey and Gates 2001; Shifren and Kachorek 2003; Jacobson and Wood 2004; Keigher et al. 2005; Bauman et al. 2006; Siskowski 2006; Diaz et al. 2007; Shifren 2008; Kavanaugh 2014). Often extensive care needs required caregiving youth to manage a variety of often complicated tasks including personal care such as feeding, toileting and dressing (Lackey and Gates 2001; Shifren and Kachorek 2003; Bauman et al. 2006; Nichols et al. 2013; Kavanaugh 2014), providing medication (Jacobson and Wood 2004), emotional care and support (Keigher et al. 2005; Bauman et al. 2006), and running errands and doing household chores (Gates and Lackey 1998; Nichols et al. 2013).

\section{Caregiving Role}

In addition to assessing tasks, understanding whether the child/youth were providing care with the assistance of someone else and length of caregiving activities is an important area. Shifren and Kachorek (2003) found the majority of adults who were caregiving youth were the primary caregivers for parents and grandparents, while Beach (1997) reported predominantly secondary caregivers. Williams et al. (2009) suggested, "other adults may be in the home (p. 281)." The national prevalence study reported that approximately $75 \%$ of young caregivers in the study were not caring for their relative alone (NAC/ UHF 2005). Bauman et al. (2006) found young caregivers often had older or young siblings present, who shared in the caregiving, while Lacky and Gates (1998) stated an adult always monitored the young carers. Although most articles mentioned/discussed the possibility of solitary caregiving, specific data about the number of caregivers within households was not uniformly collected.

Several studies did not explicitly address length of timespent caregiving (Beach 1997; Lackey and Gates 1998; Keigher et al. 2005; Siskowski 2006; Diaz et al. 2007; Cohen et al. 2012; Nichols et al. 2013), whereas others captured the duration of care in detail. Shifren and colleagues report an average of 6 years spent caregiving, while Kavanaugh (2014) found youth providing care for up to 10 years.

\section{Caregiving Outcomes}

Specific outcome measures detailed in Table 1 highlight the diverse effects of caregiving on this population. Frequently reported effects of caregiving address school performance and attendance. Indeed, several papers reported tardiness and absences, poor school performance, fatigue, and inability to complete school work (NCA/UHF 2005; Siskowski 2006; Kavanaugh 2014).

In addition to school outcomes, several studies focused on depression. Both Bauman et al. (2006) and Kavanaugh (2014) measured children's depression using the Children's Depression Inventory (CDI) (Kovacs 1992). Shifren and colleagues (Shifren 2001, 2008; Shifren and Kachorek 2003; Shifren and Chong 2012) used the Center for Epidemiologic Studies Depression scale (CES-D). Cohen et al. (2012), analyzed secondary data collected as part of the "What Works" survey, which included the Behavior Problems Index (BPI), as did the national prevalence study (NAC/UHF 2005).

Moreover, several studies addressed how caregiving impacts family relationships, including measures of parental bonding and attachment. Bauman et al. (2006) used a revised Inventory of Parent and Peer Attachment (IPPA) to measure aspects of parent relationships with caregivers, while Shifren and associates used the Parental Bonding Instrument (PBI) (Shifren and Kachorek 2003; Shifren 2008). Bauman et al. (2006) and Kavanaugh (2014) also both measured interactions with the ill parent using the Conflict Behavior Questionnaire.

Finally, several measures addressed impact in terms of the intensity of caregiving activities or level of responsibility. Bauman et al. (2006) collected data on the number of hours caregivers spent on chores. Kavanaugh (2014) used the Multi-Dimensional Assessment of Caregiving Activities (Joseph et al. 2009), capturing a diverse range and intensity of caregiving tasks. Shifren (2001) developed the Early Caregiving Experience Questionnaire, and used it in a later study (Shifren and Kachorek 2003). Gates and Lackey (1998) designed and implemented the Caregiving Activities Checklist and also used it in their later work (Lackey and Gates 2001).

\section{Discussion}

Caregiving youth play a vital role in the provision of family based care in the US, yet the research base is limited at best. The review identified 22 published peer-reviewed empirical papers, compared to well over 2000 adult caregiving papers, detailing a small, disparate research knowledge base addressing a population estimated at over 1.4 million caregiving youth (NCA/UHF 2005). In 
contrast, England and Wales have approximately 432,250 young carers out of a population of 64 million (ADASS 2014), Australia has 119,441 young carers out of a population of 23 million (Cass et al. 2009, p. 31), and Canada has 1.18 million young carers out of a population of 35 million (Stamatopoulos 2015a, b). Thus, with a population of 318.9 million, the lack of attention in the US in contrast to other developed but much smaller populated countries is pointed. The need exists to increase not only the number of studies, but also the complexity in how we understand young caregivers in the US. The US studies were largely descriptive, highlighting the gap in our understanding of more complex and nuanced analyses of their experiences. With little data on predictors, mediators and moderators of well-being, the development of programs and policies targeting this young population will be hindered by the lack of detailed and complex data.

The review also highlighted an important difficulty in defining these young caregivers, including the lack of a consistent age range. This is a critical issue since national and state policies providing funding for caregiver programs and services use age at entry criteria age, with many beginning at age 18 (NAC/AARP 2015). Defining a criterion age for youth requires discussions about policies for separate qualifications for caregiving services with an entry and exit age or wrapping youth into adult caregiving services. This struggle is underscored in the international variations in nomenclature defining what it means to be a young caregiver, with most countries using the term "young carer" (i.e., UK, Australia, Africa, Canada, Germany Austria, Iceland), but with others using variants from "young informal carer" (YIC) in Sweden, "young caregiver" in Netherlands, and "next of kin" in Norway. As evidenced in the review findings, defining young caregivers goes beyond the choice of wording, to include numerous constructs from age to experiences. However, for future directions and research, a common definition and nomenclature will be important as the field of caregiving research moves forward, particularly in terms of how to devise and administer programs. Devising young caregiver programs is vital, given the broad and often complex caregiving experiences of these isolated young caregivers.

Given the potential for negative impacts of complex caregiving tasks on children at earlier developmental stages, the young caregiving experience may be considered "off-time" with tasks traditionally performed by adults (Neugarten 1979). Indeed the review revealed youth involved in a variety of complex caregiving tasks, including those not typically associated with adolescents-toileting, bathing, feeding-over an extended period of time. Several studies consistently reported that the modal duration of care was between 1 and 4 years, and some of the studies also reported a mean duration of care greater than
6 years (Shifren 2008; Shifren and Chong 2012; Kavanaugh 2014).

Furthermore, youth provide care for a variety of medical conditions ranging from diabetes to Huntington's disease, and may be the sole caregiver for a parent, grandparent or other family member. Congruent with the international literature, US youth caregivers experienced social, psychological, health and educational problems as a result of their responsibilities and stress, underscoring the universal experience of being a child caregiver, the impact of "offtime" experiences on adolescents, and the need for strong social supports and policies non-existent in the US.

The review strengthens our understanding of caregiving youth by coalescing the current research base of caregiving youth in the US. Yet, despite the knowledge gained of existing young caregiver research, perhaps the most vital aspect of the review is what else the review highlighted: the numerous gaps in US caregiving youth research. These gaps are found at several levels, from specific caregiving youth and family demographics, to broad national awareness. Addressing the gaps will serve to inform policy and program development, and represent the many opportunities to further understand the experiences, isolation, and need for program and supports with caregiving youth.

\section{Gaps in Caregiving Youth Research}

\section{Caregiving Youth Data}

Race/Ethnicity While several studies addressed caregivers across race and ethnicity, the results did not allow us to surmise how the caregiving experience varies by these influences and how the role of culture influences family reliance on youth caregivers. Given the clear health and social disparities by race and ethnicity in the US (Williams and Jackson 2005; Krieger et al. 2005), understanding how these relate to the caregiving youth experience is vital. The adult caregiving literature identifies differential experiences across racial and ethnic groups (Connell and Gibson 1997; Aranda and Knight 1997), highlighting the role cultural expectations and norms play in the experiences of providing care and specific ways to support caregivers. Indeed, results from the Australia census indicated that youth from indigenous and culturally diverse backgrounds were more likely to be young carers than other young people (Cass et al. 2009), while Canadian census data revealed it was youth from those areas across Canada with the highest proportions of indigenous populations (i.e., Northern Canada) who had the greatest proportion of young carers (Stamatopoulos 2015a). The US literature did little to expose variations across race and culture as well as how associated norms or experiences might vary in children and youth who provide care. Thus, further exploration 
of the role of culture in the lives of young/youth caregivers is warranted to assess the true experiences across groups of caregiving youth.

Social Support With few exceptions (Shifren 2008; Kavanaugh et al. 2015), a focus on social support and caregiving youth support needs is largely missing from the literature, despite the role of perceived social support in positive emotional and interpersonal outcomes in noncaregiving adolescents (Demaray and Malecki 2002). This is a glaring omission given the extensive coverage in the adult caregiving literature (Schultz and Martine 2004; Cannuscio et al. 2004) that is informing the development of numerous state and national programs targeting adult family caregivers. Caregiver youth studies must include social support needs, including how this group defines their needs and resources to support them, thus lessening the isolation many describe. Evidence from the AACY (2015) project clearly described interventions for how schools can support and educate caregiving youth to reduce isolation and increase peer acknowledgement and support, yet few school based programs exist.

Although schools are pivotal systems to provide support, other avenues for support remain unaddressed, pointedly the medical community. Given the vital role medical professionals play in the lives of ill adults, as well as promoting positive health and well-being of children and youth, it is crucial to engage medical professionals, including physicians, nurses, psychologists, and social workers, around caregiving youth experiences, needs and supports from a medical perspective. Indeed, physicians, especially pediatricians and family physicians, have begun to acknowledge their role in identifying and supporting this population (McGrath 2015).

Physical Health of Youth Caregivers The data on adult research has revealed the numerous immediate and long terms effects of caregiving, including physical strain and injuries, stress, obesity and long-term chronicity (Ory et al. 1999; Kim and Schulz 2008). While Shifren and Chong (2012) reported higher levels of alcohol consumption in a retrospective sample of young carers, underscoring the need to assess health behaviors that may impact young carer well-being, no other US studies have focused on the impact of caregiving on the physical health or health behaviors of caregiving youth. However, other countries have begun attending to physical health, including the UK where young carer research has shown the risk of experiencing physical strain associated with caregiving (Aldridge and Becker 1993). In response to the increased attention paid to caregiving in the UK, the $2001 \mathrm{UK}$ census asked about caregiver health of all ages, including young/youth caregivers. The results showed that children under age
16 years who provided $20 \mathrm{~h}$ or more of caregiving rated their health as "not good" (Doran et al. 2003).

Researchers in Australia also addressed the health of young carers, finding that they were more likely to have a health condition compared to their non-caregiving peers (Bittman et al. 2004). While these results suggest that caregiving may impact the physical health of youth caregivers, the lack of knowledge about the health of caregiving youth is a serious gap, particularly in the US where rates of obesity, stress, and poor overall adolescent and youth health are on the rise. Given the increasing attention paid to the health and well-being of youth in the US, including the Robert Wood Johnson Foundation's healthy kids, healthy communities initiatives (www.healthykid shealthycommunities.org) and the national goal of healthy development, school performance, overall safety and wellbeing of children and adolescents by 2020 (Healthy people 2020), the need to assess the caregiving influence on the health of young caregivers is a glaring gap and a much needed direction for future research and programming.

\section{Family Level Data}

SES and Family Context Context is the location, both geographical and familial of a person in society (Kuh et al. 2003), and includes constructs such as socio-economic status (SES), health policy, and available resources (Elder 1998). Given the young age of many young caregivers, understanding the context and family level data surrounding young caregivers usually requires the addition of a parent or knowledge adult to the study. Yet, parents or other knowledgeable adults were frequently not included as participants in youth caregiving studies, thus limiting the ability to collect important information about the family context of caregiving. International reports often described young carers as living in single parent, low SES families (Cass et al. 2009), yet the US literature had limited data about socioeconomic status, family composition, or other situational variables that influence whether and how children provide care. The US national prevalence study found that youth caregivers also were more often in single family, low-income households (NAC/UHF 2005). However, given the above stated reliance on data obtained from youth who may not know why they are in the caregiving role, it is not clear whether this is the defining reason for relying on child caregivers in the US. Excluding the parent or ill family member misses the importance of external social context and its influence on the individual and family systems, particularly when considering the impact of caregiving, the reasons children are caregivers, and the need for holistic social supports and programs to assist young carers and their families. 
Health Care and Insurance One vital aspect of young caregiver context is the presence of health care and health care access. Pointedly missing from the US literature was the important role health insurance might play in the need for children to be caregivers. Despite provisions in the Affordable Health Care Act, many families may still struggle with access to home care. It is unclear what access families with a young caregiver have to health care and health care supportive services (e.g., physical therapy, occupational therapy, home health, visiting nurses), how this access may precipitate the need for a youth caregiver, and how health care needs intersect with culture and family level norms in the US. In the age of the Affordable Health Care Act, understanding who does and does not have access to proper care and services is vital for the health and well being of not only care recipients but also youth caregivers in the home.

\section{National Data}

Large Scale Studies/Data Given the extensive national study of adult caregivers, the most pointed gap in young caregiver research is the overall lack of national data to inform policy and programs targeted to young caregivers. The UK, Canada and Australia have included caregiving questions in their censuses for years, beginning with Canada in 1996, followed by UK and Australian censuses in 2001 and 2006, respectively (Stamatopoulos 2015a). However, no US census data exists on caregivers, either youth or adult. Conducted over a decade ago, one study in the US represents the entirety of what we know about the national prevalence or population estimates of young caregivers (NAC/UHF 2005). None have followed, in sharp contrast to several national caregiving surveys of adult caregivers conducted over the same time period (NAC/AARP 2015). These national adult surveys have led to the development, implementation, and continued support of national and statewide caregiving programs, always exclusive of caregivers under the age of 18 .

One avenue for national youth caregiver assessment is to include caregiver experiences in the numerous existing national surveys of youth, including the National Longitudinal Study of Adolescent and Adult Health (Add Health) and the Youth Risk Behavior Survey (YRBS). Indeed, the Behavioral Risk Factor Surveillance System (BRFSS), a national health-related survey of US residents, has included caregiving in several state surveys over the years, yet no data were collected on caregivers under the age of 18 years (Anderson et al. 2013). The addition of caregiving questions in these surveys would provide a more complete picture of child caregivers, their caregiving experiences, and how caregiving affects health and well-being as well as school productivity. National data also will provide an option to tie in needed family level data such as family income, socioeconomic status and insurance information, all previously highlighted.

Longitudinal Research No US or international longitudinal study has addressed the long-term impact of caregiving on children/youth. All studies were cross-sectional, eliminating the possibility of understanding how caregiving may change or impact caregiver/care-recipient outcomes over time. Follow-up studies of elder caregivers have shown complexities in outcomes and the potential for differing outcomes, both positive and negative, over time (Heru and Ryan 2006). Thus, results of long-term elder caregiving studies suggest the potential for differing outcomes in young caregivers, particularly as they move into older developmental stages. Large longitudinal studies have provided a deeper understanding of the overall lives of children and adolescents in the US for many years [i.e., Youth Risk behavior Survey (YRBS), Adolescent Health (Add health)]. Thus, including questions about caregiving experiences might identify and clarify positive and negative outcomes in youth and their families who struggle with school, caregiving, well-being, and the many challenges of daily family life.

Rights and Policies In acknowledging and supporting caregiving youth, the UK and Australia have gone so far as to develop county- and state-based rights and targeted programs for caregivers under the age of 18 years (Becker 2007) - many of which are framed within the Child rights convention-not yet ratified by the United States. Thus, options for US young caregiver rights and policies rest in the expansion of current adult based caregiver polices and programs. The National Family Caregiver Support Program (NFCSP) in the US seeks to improve the lives of caregivers by funding family caregiver support services (Feinberg and Newman 2006). However, by limiting services to those over age 18 years, caregiving youth are totally absent from US caregiving programs and services. In response to the lack of services and supports, the AACY has developed an array of school-based services and supports. While expanding across the US, they remain largely in Florida (AACY 2015). Thus, without policy development, national or even state-wide programming, caregiver youth will remain hidden.

\section{Future Directions}

While the US may not yet be poised to develop a bill of rights of caregiving youth, the country is certainly well on its way given the documented interest by US researchers to study this largely invisible population. The identified gaps detail numerous opportunities to engage caregiving youth and their 
families in multifaceted research targeting the well-being of caregiving youth and their families. In addition to individual primary data collection, the US is well positioned to develop large-scale studies and longitudinal projects, which will drive policies for caregiving youth, including the need to lower the age-range limits for caregiving policies and supports. An additional promising avenue lies with multicultural, multiregional, and multinational (3M) survey research, which in other research areas has proved highly effective in creating standardized cross-national instruments to measuring phenomenon of interest. Given that young carer research is still in a relative stage of development, with the exception of the UK and possibly Australia, a global social survey program dedicated to child caregivers would be an excellent opportunity to bring international experts together to produce a single survey instrument that best measures young carers and their unique caregiving experiences (Stamatopoulos 2015a).

\section{Conclusion}

This article provides the first review of caregiving youth (i.e., young carer) research in the US, summarizing both the state of current research, and gaps in US young caregivers. Caregiving youth are involved in numerous, often long lasting and complicated caregiving tasks for a variety of illnesses including diabetes, Alzheimer's and Huntington's disease. Their school performance and attendance, mental health and well-being are clearly impacted, yet despite extensive adolescent well-being research in the US (Schlabach 2013), we know very little about how constructs long known to affect adolescent well being (i.e., race, ethnicity, SES, social support), affect caregiving youth. Thus, this review provides a road map for addressing knowledge gaps in how youth-based caregiving is ameliorated or exacerbated by race/ethnicity and cultural expectations, lack of, or access to, health care, family SES, non-existent support programs and state and national caregiving polices. Addressing these gaps raises caregiving youth awareness, while providing a guide to developing new research avenues, including inclusion of caregiving in national adolescent assessment tools, and informing support programs and policies for isolated and unacknowledged caregiving youth and their families.

Acknowledgments The authors gratefully acknowledge the assistance of Dr. Connie Siskowski for her caregiving youth expertise and consultation in the design, and Dr.'s Betty J. Kramer and Nadine Marks, who provided the initial guidance on earlier drafts of this manuscript.

Author Contributions M.S.K. conceived of the study, participated in its creation, coordination, and drafting the manuscript and table;
V.S. participated in drafting sections of the manuscript and editing the manuscript; D.C. participated in editing manuscript and table creation; L.Z. participated in literature review and table design. All authors read and approved the final manuscript.

\section{Complice with Ethical Standards}

Conflicts of interest The authors report no conflict of interests.

\section{References}

Aldridge, J., \& Becker, S. (1993). Children who care: Inside the world of young carers. Loughborough University: Young Carers Research Group.

American Association of Caregiving youth. (2015). Retrieved May 5, 2015, from http://www.aacy.org/.

Anderson, S., Allen, P., Peckham, S., \& Goodwin, N. (2008). Asking the right questions: Scoping studies in the commissioning of research on the organisation and delivery of health services. Health Reaserch, Policy and Systems. doi:10.1186/1478-4505-67.

Anderson, L., Edwards, V., Pearson, W., Talley, R., McGuire, L., \& Andresen, E. (2013). Adult caregivers in the United States: Characteristics and differences in well-being, by caregiver age and caregiving status. Preventative and Chronic Disorders. doi: $10.5888 /$ pcd10.130090.

Aranda, M., \& Knight, B. (1997). The Influence of ethnicity and culture on the caregiver stress and coping process: A sociocultural review and analysis. Gerontologist, 37(3), 342-354.

Arksey, H., \& O'Mallley, L. (2005). Scoping studies: Towards a methodological framework. International Journal of Social Research Methodology, 8(1), 19-32.

Association of Directors of Adult Social Services (ADASS). (2014). Census 2011 Briefing-Age Statistics. http://www.adass.org.uk/ AdassMedia/stories/Carers/Census202011\%20briefing\% 20Age $\% 20$ statistics $\% 2016 \% 2005 \% 202013$.pdf. Accessed 23 May.

Bauman, L., Foster, G., Johnson-Silver, L., Berman, R., Gamble, I., \& Muchaneta, L. (2006). Children caring for their ill parents with HIV/AIDS. Vulnerable Children and Youth Studies, 1(1), 56-70.

Beach, D. L. (1997). Family caregiving: Positive impact on adolescent relationships. The Gerontologist, 37(2), 233-238.

Becker, S. (2007). Global perspectives on children's unpaid caregiving in the family research and policy on "young carers" in the U.K., Australia, the USA and Sub-Saharan Africa. Global Social Policy, 7(1), 23-50.

Bittman, M., et al. (2004). Identifying isolated carers: Contacting carers with unmet needs for information and support. Sydney: Social Policy Research Centre, University of New South Wales.

Boszormenyi-Nagy, I., \& Sparks, G. (1973). Invisible loyalties: Reciprocity in intergenerational family therapy. New York, NY: Harper and Row.

Cannuscio, C., Colditz, G., Rimm, E., Berkman, L., Jones, C., \& Kawachi, I. (2004). Employment status, social ties, and caregivers' mental health. Social Science and Medicine, 58, 1247-1256.

Cass, B., Smyth, C., Hill, T., Blaxland, M., \& Hamilton, H. (2009). Young carers in Australia: Understanding the advantages and disadvantages of their care-giving. Social Policy Research 16. Paper no. 38. Canberra: Australian Government Department of Families, Housing, Community Services and Indigenous Affairs.

Cohen, C., Colantonio, A., \& Vernich, L. (2002). Positive aspects of caregiving: Rounding out the caregiver experience. International Journal of Geriatric Psychiatry, 17, 184-188. 
Cohen, D., et al. (2012). Impact of family caregiving by youth on their psychological well-being. A latent trait analysis. The Journal of Behavioral Health Services \& Research, 39(93), $245-256$.

Connell, C., \& Gibson, G. (1997). Racial, ethnic, and cultural differences in dementia caregiving: Review and analysis. Gerontologist, 37(3), 355-364.

Daudt, H., van Mossel, C., \& Scott, S. (2013). Enhancing the scoping study methodology: A large, inter-professional team's experience with Arksey and O'Malley's framework. BMC Medical Research Methodology. doi:10.1186/1471-2288-13-48.

Demaray, M. K., \& Malecki, C. K. (2002). Critical levels of perceived social support associated with student adjustment. School Psychology Quarterly, 17, 213-241.

Diaz, N., Siskowski, C., \& Connors, L. (2007). Latino young caregivers in eth United States: Who are they and what are the academic implications of this role? Child \& Youth Care Forum, $36,131-140$.

Doran, T., Drever, F., \& Whitehead, M. (2003). Health of young and elderly informal caregivers: Analysis of U.K. census data. British Journal of Medicine, 327, 1388.

Elder, G. (1998). The life course as a developmental theory. Child Development, 69(1), 1-12.

Feinberg, L. (2006). How far has family caregiving come? A 30 year perspective. Aging Today, 27(4), 3-4.

Feinberg, L., \& Newman, S. (2006). Preliminary experiences of the states in implementing the national family caregiver support program: A 50-state study. Journal of Aging and Social Policy, 18(3/4), 95-113.

Friedman, M., Bowden, V., \& Jones, E. (2003). Family nursing: Research theory and practice (5th ed.). Upper Saddle River, NJ: Prentice Hall.

Gates, M., \& Lackey, N. (1998). Youngsters caring for adults with cancer. Image: Journal of Nursing Scholarship, 30(1), 11-15.

Given, B., Wyatt, G., Given, C., Sherwood, P., Gift, A., DeVoss, D., \& Rahbar, M. (2004). Burden and depression among caregivers of patients with cancer at the end of life. Oncology Nursing Forum, 31(6), 1105-1115.

Haley, W. (1997). The family caregiver's role in Alzheimer's disease. Neurology, 48(5), S25-29.

Hamill, S. B. (2012). Caring for grandparents with Alzheimer's disease: help from the "forgotten" generation. Journal of Family Issue, 33(9), 1195-1217.

Heru, A., \& Ryan, C. (2006). Family functioning in the caregivers of patients with Dementia: One year follow-up. Bulletin of the Menninger Clinic, 70(3), 222-231.

Jacobson, S., \& Wood, F. (2004). Contributions of children to the care of adults with diabetes. The Diabetes Educator, 30(5), 820-826.

Joseph, S., Becker, S., Becker, F., \& Regel, S. (2009). Assessment of caring and its effects in young people: Development of the Multidimensional Assessment of Caring Activities Checklist (MACA-YC18) and the Positive and Negative Outcomes of Caring Questionnaire (PANOC-YC20) for young carers. Child: Care, Health and Development, 35(4), 510-520.

Kavanaugh, M. (2014). Children and adolescents providing care to a parent with Huntington's disease: Disease symptoms, caregiving tasks and young carer well-being. Child \& Youth Care Forum, 43(6), 675-690.

Kavanaugh, M., Noh, H., \& Studer, L. (2015). "It'd be nice if someone asked me how I was doing. Like, 'cause I will have an answer". Exploring support needs of young carers of a parent with Huntington's disease. Vulnerable Children and Youth Studies, 10(1), 12-25.

Keigher, S., Zabler, B., Robinson, N., Fernandez, A., \& Stevens, P. (2005). Young caregivers of mothers with HIV: Need for supports. Children and Youth Services Review, 27, 881-904.
Kim, Y., \& Schulz, R. (2008). Family caregivers' strains: Comparative analysis of cancer caregiving with dementia, diabetes and frail elderly caregiving. Journal of Aging and Health, 20(3), 483-503.

Klassen, A., Raina, P., Reineking, S., Dix, D., Pritchard, S., \& O'Donnell, M. (2007). Developing a literature base to understand the caregiving experience of parents of children with cancer: A systematic review of factors related to parental health and well-being. Support Cancer Care, 15, 807-818.

Kovacs, M. (1992). Children's depression inventory. North Tonawanda, NY: Multi-Health Systems.

Kramer, B. (1997). Gain in the caregiving experience: Where are we? What next? The Gerontologist, 37(2), 228-232.

Krieger, N., Chen, J., Waterman, P., Rehnkopf, D., \& Subramanian, S. V. (2005). Painting a truer picture of US socioeconomic and racial/ethnic health inequalities: The public health disparities geocoding project. American Journal of Public Health, 95(2), 312-323.

Kuh, D., Ben-Shlomo, Y., Lynch, J., Hallqvist, J., \& Power, C. (2003). Life course epidemiology. Journal of Epidemiology and Community Health, 57, 778-783.

Lackey, N. R., \& Gates, M. F. (1997). Combining the analyses of three qualitative data sets in studying young caregivers. Journal of Advanced Nursing, 26, 664-671.

Lackey, N., \& Gates, M. (2001). Adults' recollections of their experiences as young caregivers of family members with chronic illnesses. Journal of Advanced Nursing, 34(3), 320-328.

McGrath, M. (2015). Hidden population: More than a million youths taking on caregiving role need support to shoulder heavy responsibilities. AAP News, 36(3), 12.

National Alliance for caregiving/American Association or Retired Persons. (2015). Caregiving in the U.S. Report of findings. National Alliance for Caregiving: Bethesda, MD.

National Alliance for Caregiving/United Hospital Fund. (2005). Young caregivers in the U.S.: Report of findings. National Alliance for Caregiving: Bethesda, MD.

Neugarten, B. (1979). Time, age, and the life cycle. The American Journal of Psychiatry, 136(7), 887-894.

Newman, T. (2002). Young carers and disabled parents: Time for a change of direction? Disability and Society, 17(6), 613-625.

Nichols, K. R., et al. (2013). When dementia is in the house: Needs assessment survey for young caregivers. The Canadian Journal of Neurological Sciences, 40(1), 21-28.

Oliver, S. (2001). Marking research more useful: integrating different perspectives and different methods. In S. Oliver \& G. Peersman (Eds.), Using research for effective health promotion (pp. 167-179). Buckingham: Open University Press.

Ory, M., Hoffman, R., Yee, J., Tennestedt, S., \& Schulz, R. (1999). Prevalence and impact of caregiving: A detailed comparison between dementia and non-dementia caregivers. The Gerontologist, 39(2), 177-185.

Savage, S., \& Bailey, S. (2004). The impact of caring on caregivers' mental health: A review of the literature. Australian Health Review, 27(1), 111-117.

Schlabach, S. (2013). The importance of family, race, and gender for multiracial adolescent well-being. Family Relations, 62(1), 154-174.

Schlarmann, J. G., Metzing-Blau, S., \& Schnepp, W. (2011). Implementing and evaluating the first german young-carers project: Intentions, pitfalls and the need for piloting complex interventions. The Open Nursing Journal, 5, 38.

Schulz, R., \& Martire, L. (2004). Family caregiving of persons with dementia. American Journal of Geriatric Psychiatry, 12(3), 240-249.

Schulz, R., O’Brien, A., Bookwala, J., \& Fleissner, K. (1995). Psychiatric and physical morbidity effects of dementia 
caregiving: Prevalence, correlates and causes. The Gerontologist, 35(6), 771-791.

Shifren, K. (2001). Early caregiving and adult depression good news for young caregivers. The Gerontologist, 41(2), 188-190.

Shifren, K. (2008). Early caregiving: Perceived parental relations and current social support. Journal of Adult Development, 19(2), $11-121$.

Shifren, K., \& Chong, A. (2012). Health-related behaviors: A study among former young caregivers. Journal of Adult Development, 19(2), 111-121.

Shifren, K., \& Kachorek, L. (2003). Does early caregiving matter? The effects on young caregivers' adult mental health. International Journal of Behavioral Development, 27(4), 338-346.

Siskowski, C. (2006). Young caregivers: Effects of family health situations on school performance. Journal of School Nursing, 22(3), 163-169.

Siskowski, C., Diaz, N., Connors, L., \& Mize, N. (2007). Recognition and assessment of caregiving youth in hospice and home healthcare. Home Healthcare Nurse, 25(7), 433-438.

Skaff, M., Pearlin, L., \& Mullan, J. (1996). Transitions to caregiving career: Effects on sense of mastery. Psychology and Aging, 11(2), 247-257.
Stamatopoulos, V. (2015a). One million and counting: The hidden army of young carers in Canada. Journal of Youth Studies, 18(6), 809-822.

Stamatopoulos, V. (2015b). Supporting young carers: A qualitative review of young carer services in Canada. International Journal of Adolescence and Youth. doi:10.1080/02673843.2015. 1061568.

Stetz, K., \& Brown, M. (2004). Physical and psychosocial health in family caregiving: A comparison of AIDS and cancer caregivers. Public Health Nursing, 21(6), 533-540.

Sulkers, E., et al. (2015). Providing care to a child with cancer: A longitudinal study on the course, predictors, and impact of caregiving stress during the first year after diagnosis. Psychooncology, 24(3), 318-324.

Viola, D., Arno, P., Siskowski, C., Cohen, D., \& Gusmano, M. (2012). The economic value of youth caregiving in the United States. Relational Child and Youth Care Practice, 25(2), 10-13.

Williams, J. K., Ayres, L., Specht, J., Sparbel, K., \& Klimek, M. L. (2009). Caregiving by teens for family members with Huntington disease. Journal of Family Nursing, 15, 273-294.

Williams, D., \& Jackson, P. (2005). Social sources of racial disparities in health. Health Affairs, 24(2), 325-334. 